\title{
Acetabular Reconstruction with Impaction Bone-Grafting and a Cemented Cup in Patients Younger than Fifty Years Old
}

\author{
A Concise Follow-up, at Twenty to Twenty-eight Years, of a Previous Report*
}

\author{
By Vincent J.J.F. Busch, MD, Jean W.M. Gardeniers, MD, PhD, Nico Verdonschot, PhD, \\ Tom J.J.H. Slooff, MD, PhD, and B. Willem Schreurs, MD, PhD \\ Investigation performed at Radboud University Nijmegen Medical Centre, Nijmegen, The Netherlands
}

\begin{abstract}
In a previous report, we presented our results of forty-two acetabular reconstructions, performed with use of impaction bone-grafting and a cemented polyethylene cup, in thirty-seven patients who were younger than fifty years and had a minimum of fifteen years of follow-up. The present update study shows the results after twenty to twenty-eight years. Eight additional cups had to be revised-four because of aseptic loosening, three because of wear, and one during a revision of the stem. Three additional cups were considered loose on radiographs. Survivorship of the acetabular reconstructions, with an end point of revision for any reason, was $73 \%$ after twenty years and $52 \%$ after twenty-five years. With revision for aseptic loosening as the end point, survival was $85 \%$ after twenty years and $77 \%$ after twenty-five years; for signs of loosening on radiographs, survival was $71 \%$ at twenty years and $62 \%$ at twenty-five years. In conclusion, our previous results have declined but the technique of using impacted morselized bone graft and a cemented cup is useful for the purpose of restoring bone stock in young patients whose acetabular defects require primary or revision total hip arthroplasty.
\end{abstract}

Level of Evidence: Therapeutic Level IV. See Instructions to Authors for a complete description of levels of evidence.

\section{Background}

Dreviously, we reported the clinical and radiographic outcomes of forty-two consecutive acetabular reconstructions performed with use of an impaction bone-grafting technique and a cemented cup in thirty-seven patients who were all younger than fifty years (average, thirty-seven years; range, twenty to forty-nine years) at the time of surgery ${ }^{1}$. We used impaction bone-grafting as a biological technique to reconstruct acetabular deficiencies in younger patients. This reconstructive technique was used in twenty-three primary and nineteen revision operations. The average follow-up in that study was seventeen years and six months (range, fifteen to twenty-three years). Kaplan-Meier analysis showed that the probability of survival of the acetabular component at fifteen years was $83 \%$ ( $95 \%$ confidence interval, $72 \%$ to $96 \%$ ) with the end point being revision of the cup for any reason and $94 \%$ (95\% confidence interval, $87 \%$ to $100 \%$ ) with the end point being revision of the cup for aseptic loosening ${ }^{1}$. The overall radiographic survival rate of the cup was $89 \%$ ( $95 \%$ confidence interval, $80 \%$ to $99 \%$ ) at fifteen years.

The purpose of the present study was to update the clinical and radiographic results of our previous report after a mean duration of follow-up of twenty-three years (range, twenty to twenty-eight years).

\section{Methods}

The study was approved by our institutional review board. 1 Between July 1979 and December 1987, we performed fortytwo consecutive acetabular reconstructions, with use of an impaction bone-grafting technique and a cemented polyethylene cup, in thirty-seven patients who had deficient acetabular bone stock and who were younger than fifty years at the time of the

*Original Publication

Schreurs BW, Busch VJJF, Welten ML, Verdonschot N, Slooff TJJH, Gardeniers JWM. Acetabular reconstruction with impaction bone-grafting and a cemented cup in patients younger than fifty years old. J Bone Joint Surg Am. 2004;86:2385-92.

Disclosure: In support of their research for or preparation of this work, one or more of the authors received, in any one year, outside funding or grants of less than $\$ 10,000$ from Stryker (United Kingdom). Neither they nor a member of their immediate families received payments or other benefits or a commitment or agreement to provide such benefits from a commercial entity. 
The Journal of Bone \& Joint Surgery · Jbjs.org Volume 93-A · Number 4 - February 16, 2011
Acetabular Reconstruction with Impaction Bone-Grafting and a Cemented Cup in Patients Younger than Fifty Years Old operation. It was the only technique used in our department to treat acetabular bone stock loss. After a posterolateral approach and resection of the femoral head or removal of failed components, the acetabulum was reamed to create a bleeding bone bed. Segmental defects were reconstructed with use of a metal mesh or a solid graft. Before impaction, remaining sclerotic areas were perforated with multiple 2 -mm drill-holes. In primary acetabular reconstructions, the femoral head was morselized with a rongeur to create cancellous bone chips with a diameter of 0.7 to $1.0 \mathrm{~cm}$. In hips with larger defects or when revision surgery was being performed, fresh-frozen nonirradiated femoral head allografts were used. In some early cases, bone grafts were taken from the iliac crest. After lavage of the acetabulum, the grafts were impacted with use of impactors and a mallet. The defect was reconstructed, layer by layer, until the defect was restored completely. Bone cement was pressurized into the impacted grafts with use of a seal. Before 1989, we used Palacos bone cement (Merck, Darmstadt, Germany), and, from 1989 on, we used Surgical Simplex bone cement (Stryker Howmedica, Newbury, United Kingdom). Regular bone cement was used for the primary arthroplasties, whereas gentamicin-impregnated cement was used for the revisions. To create a sufficient cement mantle, the last trial prosthesis that was used for impaction was at least $2 \mathrm{~mm}$ larger than the proposed cup. In the present series, twenty-five 32-mm Müller and seventeen 32-mm Allopro all-polyethylene cups (Sulzer, Winterthur, Switzerland) were used. Both components were manufactured from compression-molded GUR 412 (RCH-1000; Ruhrchemie, Oberhausen, Germany) and sterilized by gamma radiation in air. Sixteen cemented Charnley-Müller curved stems (Protek AG, Bern, Switzerland), twenty-five cemented M.E. Müller straight stems (Protek AG), and one cemented Stanmore prosthesis (Biomet, Bridgend, United Kingdom) were used, all with a head size of $32 \mathrm{~mm}$.

For this report, we reviewed all reconstructions (twentythree [55\%] primary and nineteen [45\%] revision total hip reconstructions) at a minimum period of follow-up of twenty years. All patients were prospectively followed annually or biennially for at least twenty years, or until revision or death.

Acetabular defects were classified according to the classification system of the American Academy of Orthopaedic Surgeons (AAOS) Committee on the Hip ${ }^{2}$ (Table I). Radiographic evidence of bone-graft incorporation was defined as equal radiodensity of graft and host bone, with a continuous trabecular pattern throughout, according to Conn et al. ${ }^{3}$. Radiolucent lines $>2 \mathrm{~mm}$ wide were identified in the three zones of DeLee and Charnley ${ }^{4}$. Radiolucent lines were defined as stable or as progressive with time. As of the last review in 2008, all living patients with surviving hips were seen for clinical and radiographic examination and both a Harris hip score and an Oxford Hip Questionnaire Score ${ }^{5}$ were obtained. All patients who died during the period of follow-up were followed on a regular basis until their death, and their data were included in this report. Failure was defined clinically as the need for revision of the acetabular component for any reason. A radiographic failure was defined as radiolucent lines in all three zones of DeLee and Charnley, or migration of $5 \mathrm{~mm}$ or more in

\begin{tabular}{|lcc|}
\hline TABLE I Patient Demographics & & \\
\hline & Patients (no.) & Hips (no.) \\
\hline No. in series & 37 & 42 \\
Sex & & \\
F & 22 & 24 \\
M & 15 & 18 \\
Type of defects according & & \\
to AAOS classification & & 1 \\
Segmental & & 27 \\
Cavitary & & 14 \\
Combined & 8 & 10 \\
Deaths during follow-up period & 1 & 1 \\
Lost to follow-up & & 16 \\
Revisions during follow-up & & 8 \\
Due to septic loosening & & 4 \\
Due to aseptic loosening & & 2 \\
Due to wear & & \\
During stem revision & & \\
\hline
\end{tabular}

any direction relative to the interteardrop line on the anteroposterior pelvic radiograph. Linear polyethylene wear was measured according to the method described by Livermore et al. ${ }^{6}$, and the measurements were corrected for magnification.

The Kaplan-Meier analysis was performed with three different end points: revision of the acetabular component for any reason, revision of the acetabular component for aseptic loosening, and radiographic signs of failure. Kaplan-Meier survivorship analysis was performed for the whole group of hips treated with acetabular reconstruction and included $95 \%$ confidence intervals. A log-rank test was used to compare survival rates of subgroups.

\section{Source of Funding}

Funding for this study was provided by Stryker (United Kingdom).

\section{Results}

\section{Clinical Results}

f the original group of thirty-seven patients (forty-two hips), one patient (one implant) was lost to follow-up and eight patients (ten implants) had died of causes unrelated to the surgery. At the time of the final review, nineteen surviving hips were in situ in seventeen patients and were clinically and radiographically evaluated after a mean follow-up period of twenty-three years (range, twenty to twenty-eight years). Unfortunately, one patient was unable to attend due to progressive dementia; however, her relatives reported no reoperation and no apparent clinical symptoms. For radiographic analyses for this patient, we used the last radiograph available, from 2005. The mean Harris hip score of the surviving hips was 88 (range, 44 to 100), and the mean Oxford Hip Questionnaire Score was 20 (range, 12 to 41 ). 
The Journal of Bone \& Joint Surgery $\cdot$ JBjS. Org Volume 93-A · Number $4 \cdot$ February 16,2011
Acetabular Reconstruction with Impaction Bone-Grafting and a Cemented Cup in Patients Younger than Fifty Years Old

\section{Revisions}

Eight additional cups (19.5\%) had to be revised after the previous report, which meant that sixteen acetabular revisions (39\%) were performed overall. Two cups (4.9\%) were revised because of culture-proven septic loosening after three and 14.5 years. Eight reconstructions (19.5\%) failed because of aseptic loosening and were revised after a mean of 17.3 years (range, 6.4 to 25.5 years), including four with a cavitary (type-2) defect and four with a combined (type-3) defect. Four reconstructions $(9.8 \%)$ were revised because of wear and osteolysis after a mean of 18.8 years (range, 8.9 to 25.4 years). Two cups $(4.9 \%)$ were revised after 12.3 and 18.3 years during a revision of the stem because of persistent instability and matching problems. However, these six cups were both intraoperatively and radiographically well-fixed.

\section{Radiographic Results}

Follow-up radiographs were complete for thirty-seven hips $(90.2 \%)$, which were used for further analysis. Data were incomplete for two deceased patients (three hips) and for the patient with dementia, for whom the latest radiograph was used. Of the nineteen hips in seventeen patients with the implant still in situ, twelve cups appeared to be well fixed with uniform radiodensity of the graft and the host bone and without progressive radiolucent lines. Three cups $(7.3 \%)$ were considered loose radiographically. The radiographs of four additional hips showed progressive radiolucent lines (in zone three in three hips, and in zones two and three in one hip). The radiograph of one hip showed a pelvic osteolytic area in zone one. Six hips had Brooker grade-I ossification, one hip had Brooker grade-II ossification, and three hips had Brooker grade-III ossification ${ }^{7}$. The mean polyethylene wear for the whole group of living patients with the implant still in situ was $2.0 \mathrm{~mm}(0.8$ to $3.4 \mathrm{~mm})$.

Of the six surviving hips in five deceased patients, one cup showed a progressive radiolucent line in one Gruen zone ${ }^{8}$. Of the sixteen revised hips, ten showed definitive radiographic loosening of the cup. Four cups showed excessive polyethylene wear, and one of the four had associated pelvic osteolysis but migration or progressive lines in more than one zone were not seen. The remaining two cups were revised during revision of the stem and did not show progressive radiolucent lines. The mean wear of the revised cups measured $2.1 \mathrm{~mm}$ (range, 0 to $4.2 \mathrm{~mm})$.

\section{Additional Reoperations and Complications}

As noted in our previous report, four revisions of the femoral component were done and, in one patient, periarticular ossifications were removed 1.2 years postoperatively. Since the time of our previous report, there has been one additional femoral revision for aseptic loosening, and the cup was revised during the same operation. Neurapraxia of the peroneal nerve developed postoperatively in one patient but fully resolved.

\section{Survivorship Analysis}

Survivorship of the acetabular reconstructions according to the different end points is shown in Table II. With revision for any reason as the end point, survival of the acetabular component was $73 \%$ (95\% confidence interval, $58 \%$ to $87 \%$ ) at twenty years and $52 \%$ (95\% confidence interval, $35 \%$ to $72 \%)$ at twenty-five years (Fig. 1). With revision for aseptic loosening of the cup as the end point, survivorship was $85 \%$ (95\% confidence interval, $72 \%$ to $97 \%)$ at twenty years and $77 \%(95 \%$

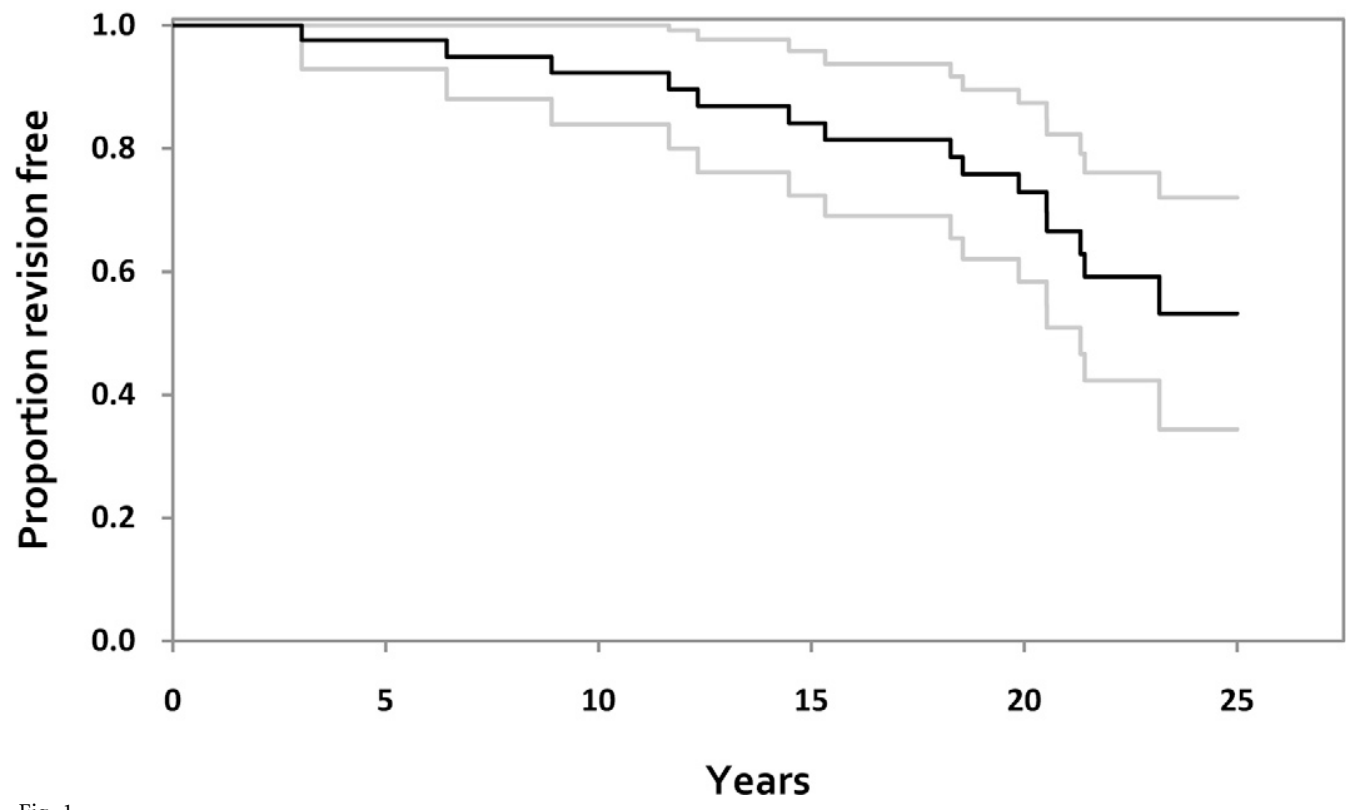

Fig. 1

Kaplan-Meier survival curve for the entire group (black line) and the upper and lower 95\% confidence intervals (gray lines), with revision of the acetabular component for any reason as the end point. 
TABLE II Survival Rates for the Different Periods of Follow-up and End Points

\begin{tabular}{|llll|}
\hline $\begin{array}{c}\text { End Point for Survivorship } \\
\text { of Reconstructions }\end{array}$ & $\begin{array}{c}\text { 15-Year Survival }(95 \% \\
\text { Confidence Interval) }\end{array}$ & $\begin{array}{c}\text { 20-Year Survival (95\% } \\
\text { Confidence Interval) }\end{array}$ & $\begin{array}{c}25-Y e a r \text { Survival (95\% } \\
\text { Confidence Interval) }\end{array}$ \\
\hline Revision for any reason & $0.84(0.72$ to 0.96$)$ & $0.73(0.58$ to 0.87$)$ & $0.52(0.35$ to 0.72$)$ \\
Aseptic loosening & $0.94(0.87$ to 1.00$)$ & $0.85(0.72$ to 0.97$)$ & $0.77(0.62$ to 0.92$)$ \\
Radiographic loosening & $0.89(0.80$ to 0.99$)$ & $0.71(0.55$ to 0.86$)$ & $0.62(0.44$ to 0.80$)$ \\
\hline
\end{tabular}

confidence interval, $62 \%$ to $92 \%$ ) at twenty-five years of follow-up. With radiographic loosening of the cup as the end point, the survivorship was $71 \%$ (95\% confidence interval, $55 \%$ to $86 \%)$ at twenty years and $62 \%$ (95\% confidence interval, $44 \%$ to $80 \%$ ) at twenty-five years. Comparison of survival rates of primary and revision reconstructions did not reveal any statistical differences.

\section{Conclusions}

The technique of impaction bone-grafting is especially attractive for the purpose of obtaining a biological repair of the acetabular bone defect and facilitating future revisions in young patients. The follow-up was nearly complete in our study, and the fate of every reconstruction is known, except in one case. Probably due to the relatively small numbers, statistical differences could not be shown between survival of hips in the primary and revision subgroups and, therefore, the data are presented as overall results.

In addition to the revised cups, three additional cups were seen to be radiographically loose and will probably need to be revised in the near future. Compared with the rates seen in our previous study, the survival rates have been deteriorating. Progressive wear and related osteolysis was seen in these younger and active patients, and this radiographic finding necessitated revision. Six of the sixteen revised acetabular components were both intraoperatively and radiographically well fixed, and this supports the hypothesis that it would not be the reconstruction itself but the secondary problems that would cause a decline in survival. The survival of $77 \%$ after twenty-five years, with an end point of revision of the cup for aseptic loosening, is comparable with long-term reports on cemented hips in young patients ${ }^{9,10}$, while we used this technique in demanding primary total hip arthroplasties and acetabular revisions.

Cementless hip designs are mostly used currently in young patients, but reports on cementless cups with bonegrafting in patients younger than fifty years old with a minimum follow-up of fifteen years are lacking. However, good results with cementless cups in combination with acetabular grafts in hip revisions are reported by several authors in older patients. In hips undergoing revision, Rudelli et al. ${ }^{11}$ showed a survival rate of $88.3 \%$ in uncemented cups, with an end point of revision for any reason, after a mean follow-up of 167 months in a group of forty-two patients (forty-three hips) with a mean age at surgery of fifty-six years. Palm et al. ${ }^{12}$ reported a nine-year survival rate of the cup of $90.5 \%$ in a group of seventy-nine patients in whom the median age was sixtyseven years. Lachiewicz and Poon ${ }^{13}$ reported the results of thirty-four patients in whom morselized bone grafts were used in combination with a Harris-Galante porous-coated cup, and no revision because of loosening had taken place after a mean follow-up of seven years for the total group of patients. Although these are good and promising mid-term results, longer follow-up is needed to prove the true clinical value of these cementless techniques in young patients.

Pelvic osteolysis, which is seen at a higher frequency about cementless components, is still an unsolved problem in young patients. In a series by Della Valle et al. ${ }^{14}$, very acceptable results were achieved with use of a porous-coated acetabular component, but osteolysis was observed in more than $30 \%$ of patients who were younger than fifty years.

The technique of reconstruction, as reported in our study, has basically remained the same over the years, with only minor changes. In the first years, a metal mesh was placed on top of the impacted bone grafts just before cementation. After one decade, we realized that this mesh was not very functional, so metal mesh is now used only to reconstruct segmental defects. In addition, our rehabilitation program has been changed, with patients now mobilized earlier with earlier weight-bearing, depending on the size of the reconstruction.

NotE: The authors thank Jan Hendriks for his excellent statistical support.

Vincent J.J.F. Busch, MD

Jean W.M. Gardeniers, MD, $\mathrm{PhD}$

Nico Verdonschot, $\mathrm{PhD}$

Tom J.J.H. Slooff, MD, $\mathrm{PhD}$

B. Willem Schreurs, MD, PhD

Department of Orthopaedics 357,

Radboud University Nijmegen Medical Centre,

P.O. Box 9101,

6500 HB Nijmegen,

The Netherlands.

E-mail address for B.W. Schreurs: b.schreurs@orthop.umcn.nl

\section{References}

1. Schreurs BW, Busch VJ, Welten ML, Verdonschot N, Slooff TJ, Gardeniers JWM. Acetabular reconstruction with impaction bone-grafting and a cemented cup in patients younger than fifty years old. J Bone Joint Surg Am. 2004;86: 2385-92. 
The Journal of Bone \& Joint Surgery $\cdot$ JBJS. Org Volume 93-A · Number $4 \cdot$ February 16,2011

2. D'Antonio JA, Capello WN, Borden LS, Bargar WL, Bierbaum BF, Boettcher WG, Steinberg ME, Stulberg SD, Wedge JH. Classification and management of acetabular abnormalities in total hip arthroplasty. Clin Orthop Relat Res. 1989;243:126-37.

3. Conn RA, Peterson LFA, Stauffer RN, Ilstrup DM. Management of acetabular deficiency; long-term results of bone-grafting the acetabulum in total hip arthroplasty. Orthop Trans. 1985;9:451-2.

4. DeLee JG, Charnley J. Radiological demarcation of cemented sockets in total hip replacement. Clin Orthop Relat Res. 1976;121:20-32.

5. Dawson J, Fitzpatrick R, Carr A, Murray D. Questionnaire on the perceptions of patients about total hip replacement. J Bone Joint Surg Br. 1996;78:185-90.

6. Livermore J, Ilstrup D, Morrey B. Effect of femoral head size on wear of the polyethylene acetabular component. J Bone Joint Surg Am. 1990;72:518-28.

7. Brooker AF, Bowerman JW, Robinson RA, Riley LH Jr. Ectopic ossification following total hip replacement. Incidence and a method of classification. J Bone Joint Surg Am. 1973;55:1629-32.

8. Gruen TA, McNeice GM, Amstutz HC. "Modes of failure" of cemented stem-type femoral components: a radiographic analysis of loosening. Clin Orthop Relat Res. 1979;141:17-27.
Acetabular Reconstruction with Impaction Bone-Grafting and a Cemented Cup in Patients Younger than Fifty Years Old

9. Keener JD, Callaghan JJ, Goetz DD, Pederson DR, Sullivan PM, Johnston RC. Twenty-five-year results after Charnley total hip arthroplasty in patients less than fifty years old: a concise follow-up of a previous report. J Bone Joint Surg Am. 2003; 85:1066-72.

10. Sochart DH, Porter ML. Long-term results of total hip replacement in young patients who had ankylosing spondylitis. Eighteen to thirty-year results with survivorship analysis. J Bone Joint Surg Am. 1997;79:1181-9.

11. Rudelli S, Honda E, Viriato SP, Libano G, Leite LF. Acetabular revision with bone graft and cementless cup. J Arthroplasty. 2009;24:432-43.

12. Palm L, Jacobsson SA, Kvist J, Lindholm A, Ojersjö A, Ivarsson I. Acetabular revision with extensive allograft impaction and uncemented hydroxyapatite-coated implants. Results after 9 (7-11) years follow-up. J Arthroplasty. 2007;22:1083-91.

13. Lachiewicz PF, Poon ED. Revision of a total hip arthroplasty with a Harris Galante porous-coated acetabular component inserted without cement. A follow-up note on the results at five to twelve years. J Bone Joint Surg Am. 1998;80:980-4.

14. Della Valle CJ, Mesko NW, Quigley L, Rosenberg AG, Jacobs JJ, Galante JO. Primary total hip arthroplasty with a porous-coated acetabular component. A concise follow-up, at a minimum of twenty years, of previous reports. J Bone Joint Surg Am. 2009;91:1130-5. 